\title{
PETA PEMIKIRAN FIQH PASCA MADZHAB
}

\author{
Tobibatussaadah \\ Institut Agama Islam Negeri (IAIN) Metro \\ Email: tobibah_saadah@yahoo.co.id
}

\begin{abstract}
The period of the development of madzhab experienced ups and downs, during its golden age the scientific development in heretical figh was very rapid, the scales of mujtahid mutlaq were in the golden age. After generalization of the school of Islamic legal thought has stagnated, this attitude can be seen from the behavior of Muslims after the school of Nostalgia in the past and the assumption that the established school of thought has crystallized in Muslims in that period. This research is a literature study that will explore the post-madzhab thought map of figh. The result of the research is that the development of figh thought has stagnated, which occurs only by practicing taqlid to the existing schools of thought, and the cultural errors of syarah and hasyiyah. They no longer try to solve the prolematics of their time based on existing realities. So that the teachings of Islam are only limited to theory and ritual, not applicable as positive law for its people in all aspects of life.
\end{abstract}

Keywords: Thought, Figh, Post, Madzhab.

\section{A. Pendahuluan}

Dalam sejarah, hukum Islam berkembangan secara fluktuatif. Masa tashri' hingga periode mazhab, hukum Islam mencapai puncak. Pada masa tersebut, universalitas ajaran Islam mampu diterjemahkan dalam konteks waktu dan keadaan. Sehingga ajaran Islam menjadi referensi primer merespon dinamika umat manusia yang terus maju. Dalam hitungan sejarawan, periode tersebut mulai dari masa Rasulullah saw. hingga masa tabi' tabi'un.

Dalam perkembangannya Islam sebagai ajaran universal dan berperadaban tidak terlihat lagi. Pada masa ini, Islam terlihat sebagai ajaran kuno dimana hukumnya tidak sesuai dengan peradaban manusia terkini. Kuno yang penulis maksudkan adalah, norma-norma dan kaidah dalam menggali hukum Islam masih mendasari kepada teori zaman dahulu. Sedangkan disisi lain life style manusia terus bergerak dan fenomena demikian merupakan sunnatullah. Untuk melogiskannya, penulis ungkapkan penjelasan Ilmu Mantiq yaitu, 'Alam berubah-berubah, dan setiap yang berubah adalah baharu, alam adalah baharu (dinamis) tidak statis.'

Statisnya ajaran Islam karena sikap stagnasi umat Islam dalam memperkuat tsaqafah (intelektual) sebagai topangnya hadharah (peradaban). Sikap ini terlihat dari perilaku umat Islam yang bertaqlid kepada mazhab yang telah ada, dan munculnya budaya syarah dan hasyiyah. Mereka tidak berusaha lagi menyelesaikan prolematika dimasanya berdasarkan realitas yang ada. Nostalgia masa lalu dan anggapan telah mapannya mazhab yang dianut telah mengkristal dalam diri umat Islam dalam periode tersebut. Sehingga ajaran Islam hanyalah sebatas teori dan ritual saja bukan aplikatif sebagai hukum positif bagi umatnya dalam segala aspek kehidupan. 


\section{B. Pembahasan}

\section{B.1. Kondisi Fiqh Pasca Madzhab}

Fiqh saat pembentukan mazhab, secara langsung melàlui tangan para murid yang telah berhasil menyusun hasil Ijtihad pendahulunya atau gurunya dalam bentuk kitab fiqh sebagai panduan beramal. Setelah tergeneralisasi madzhab, kemudian sampai abad ke 7 kondisi pemikiran umat Islam semakin melemah, hal ini ditunjukan dengan tidak berdayaan umat Islam untuk mencurahkan pemikiran dalam bentuk ijtihad yang baru, pemikiran-pemikiran kritis, dan pemikiran berkembang sudah tidak nampak lagi, sehingga pemikiran umat Islam setelah terbentuknya madzhab hanyalah mengikuti madzhab yang sudah ada (taqlid), selain taqlid kebiasaan yang membuat pemikiran hukum Islam semakin melemah karena munculnya tradisi syarah dan hasyiyah, yang akan di bahas berikutnya.

\section{B.2. Masa Taqlid}

Semangat dan kemerdekaan ijtihad yang marak mewarnai aktifitas tasyri' di berbagai periode sebelumnya, seolah-olah lenyap dan diganti dengan semangat dan jiwa baru yang justru menjadi titik awal kemunduran tasyri', ya'ni taklid.

\section{Taqlid Secara Definitif}

Para ulama Ushul telah memberikan berbagai definisi untuk menjelaskan hakekat daripada taqlid, diantaranya perkataan sebagian mereka bahwa taqlid adalah menerima perkataan seseorang sementara dirinya tidak mengetahui darimana asal perkataan itu. Sebagian lainnya berpendapat bahwa taqlid adalah menerima pendapat seseorang tanpa hujjah (dalil). Sedangkan Abul Ma'ali al Juweiniy memilih definisi bahwa taqlid adalah mengikuti (seseorang) yang didalam mengikutinya itu tanpa disertai hujjah dan tidak bersandar kepada ilmu. Ibnu al Hammam dalam kitabnya at-Tahrir (w. 861 H.) taqlid adalah, amalan dengan mengikuti perkataan seseorang yang tidak tergolong sebagai salah satu argumentasi hukum, tanpa dilandasi dalil yang menunjukkan eksistensi amalan tersebut di mata hukum. ${ }^{1}$

\section{Sumber Hukum Dalam Periode Taqlid}

Merujuk kepada pengertian taqlid, maka sumber hukum golongan muqallid adalah kaidah-kaidah dan fatwa-fatwa fuqaha mazhab yang diikuti. Mereka tidak berupaya melihat apakah kaidah ijtihad tersebut sudah benar atau tidak ataupun masih relavan atau tidak dengan masa mereka. Namun mereka mengamalkan sebagaimana adanya dan tidak berupaya mencurahkan pikiran mereka untuk menciptakan teori baru dalam berijtihad sebagaimana yang dilakukan oleh fuqaha terdahulu.

Pada periode ini mayoritas umat Islam bertaqlid kepada mazhab Hanafiy, Maliki, Shafi'y dan Hanbali. Untuk mendalami mazhab masing-

1 Yusuf Al-Qaradhawi dan Kaifa, Nata'aamalu Ma'a Tiraatsi Wa Tamazzahabi Wal Iktilaafi, Terj. Abdul Hayyie al-Kattani, Atik Fikri Ilyas dan Ahmad Ichwani, Memahami Khazanah Klasik, Mazhab dan Ikhtilaf, (Jakarta: Akbar Media Eka Sarana), h. 85. 
masing, umat Islam menSharah kembali mazhab mereka dan penSharah tersebut tampil kedepan dan menjadi ulama bagi umat Islam dimasanya.

Tentang perilaku taqlid, Imam Hasan al-Banna menggunakan ungkapannya dengan ittibaa' bukan taqlid. ${ }^{2}$ Ungkapan al-Banna tersebut menjadi penengah terhadap dua kutub yang berbeda dalam menilai taqlid. Kutub pertama menyatakan, taqlid terhadap mazhab adalah wajib yaitu Shaikh ash-Shawi al-Maliki dan kawan-kawan. ${ }^{3}$ Sedangkan kutub yang kedua menyatakan haram, salah satu pelopornya adalah Al-Shaukani. ${ }^{4}$

\section{Penegak Hukum Pada Periode Taqlid}

Meskipun pada periode taqlid dinyatakan sebagai fase kemunduran hukum Islam, namun kreatifitas umat Islam dalam menegakkan hukum tidak bisa dikatakan sudah berkurang dibanding ulama pendahulu mereka. Beragam persoalan baru muncul dalam kehidupan, dan persoalan tersebut harus dikuasai dan dihadapi dengan piranti tradisional yang diberikan oleh ilmu hukum. Aktivitas ini dilakukan oleh para mufti. Mereka merupakan pakar hukum yang dapat memberikan pendapat yang otoritatif tentang dokrin, dan pendapat hukum yang mereka keluarkan disebut sebagai "fatwa". Ini merupakan pemahan penulis dari laporan Joseph Schacht dalam bukunya Pengantar Hukum Islam.

Keadaan tersebut tidak berbeda dimasa tabi'in sebelum munculnya tokoh mazhab sebagai kelompok profesional semisal Al-Shafi'i yang telah diposisikan sebagai pakar yurisprudensi hukum Islam dimana implikasi dari karya besar Al-Shafi'i tersebut telah merusak pemikiran umat Islam bahwa, hanya orang-orang tertentu saja yang mampu memahami hukum Islam secara detail kendatipun Al-Shafi'i tidak mendokrin seperti itu.

Para mufti dimasa tabi'in berperan sebagai pembimbing dan pemberi nasehat kepada masyarakat tentang cara berbuat benar berdasarkan hukum Islam. Otoritas mufti bersifat pribadi karena didasarkan pada reputasi keulamaan. Pendapat seorang mufti tidak memiliki sanksi resmi, dan seseorang dapat saja meminta bantuan ulama manapun yang dikenal dan dipercayainya. Elemen cautelary dan advisory mufti jelas terlihat dalam karya Malik, khusus diskripsi tentang Ibrahim an-Nakha'i salah satu mufti dimasa tabi'in. ${ }^{5}$

Pada periode taqlid, ketika mazhab sudah dianggap mapan, pemerintah Islam mengangkat para ulama yang diakui keahlian mereka sebagai mufti resmi dan kepala mufti digelari sebagai "Shaikh Al-Islam". Kendatipun demikian, kehadiran mufti resmi sebagai stacholder pemerintah tidak menambah instrinsik dari pendapat mereka. Mereka tidak memiliki hak monopoli dalam pemberian fatwa, dan tradisi berkonsultasi kepada para

\footnotetext{
2 Yusuf Al-Qaradhawi dan Kaifa, Nata'aamalu Ma'a Tiraatsi..., h. 99.

${ }^{3}$ Ibid, h. 87.

4 Ibid, h. 95.

5 Joseph Schacht, An Introduction to Islamic Law, Terj. Joko Supomo, Pengantar Hukum Islam,
} (Bandung: Nuansa, 2010), h. 117. 
ulama yang bereputasi tinggi tetap tidak berhenti. Qadhi juga dapat berkonsultasi kepada seorang ulama bila ia merasa ragu-ragu dan para mufti resmi sering dikaitkan dengan pengadilan qadhi. Sebelum qadhi memutuskan perkara, mereka akan melengkapi diri dengan fatwa-fatwa yang seotoritatif mungkin meskipun mereka tidak terikat untuk menerima fatwa manapun. ${ }^{6}$

Setiap keputusan yang dicapai oleh seorang mufti resmi tentang perbuatan hukum baru yang dianggap benar oleh para ulama, maka keputusan itu dimasukkan dalam buku pegangan mereka. Oleh sebab itu, kontribusi mufti resmi tersebut dalam perkembangan hukum Islam sangat besar pada periode taqlid. Fatwa mereka sering dikumpulkan dalam karya terpisah yang berbicara tentang kepentingan historis yang sangat besar. Mereka menunjukkan problem-problem penting yang muncul dan praktik pada ruang dan waktu.

Demikianlah kreatifitas mufti resmi dalam meletakkan dasar hukum Islam meskipun keputusan mereka tidak mempengaruhi terhadap perkembangan hukum Islam setelah akhir periode formatifnya diawal pemerintahan Abbasiyah.

Untuk lebih jelas tentang fenomena tersebut, berdasarkan laporan Joseph Schacht bahwa, hukum Islam sampai pada permulaan Abbasiyah telah bersifat adaptif dan mengikuti perkembangan. Dan sejak itu terus bertambah semakin kaku dan memperoleh bentuknya yang bersifat final. Kekakuan ini telah mampu membantu memelihara stabilitas hukum selama berabad-abad lamanya yang memperlihatkan melemahnya lembaga-lembaga politik Islam. Memang tidak seluruhnya bersifat tetap, tetapi perubahan yang benar-benar terjadi itu lebih banyak berkaitan dengan teori hukum dan superstruktur yang sistematis dan bukan pada hukum positif. Secara keseluruhan, hukum Islam merefleksikan dan sesuai dengan kondisi sosial dan ekonomi pada periode awal Abbasiyyah. Akan tetapi hukum Islam pada akhirnya berkembang semakin jauh dari sentuhan perkembangan negara dan maSharakat kemudian. ${ }^{7}$

\section{B.3. Tradisi Sharah dan Hashiyah dalam Fiqh}

Terjadinya fenomena tradisi Syarah dan Hasiyah muncul di sebabkan karena ketidak beranian melakukan penelitian dan kajian kritis yang kemudian dirasionalisasikan dengan argumen: Apa yang telah dihasilkan para imam mazhab dan para pendukungnya sudah final dan apapun produk pemikiran mereka harus diterima sebagai berlaku "sekali untuk selamanya".8 Akibatnya, tradisi keilmuan yang berlangsung kemudian adalah tradisi sharh dan häshiah atas matan yang dirumuskan oleh ulama terdahulunya. Generasi berikutnya merasa sudah cukup atas temuan dan rumusan yang dibuat oleh generasi terdahulu, mereka hanya

${ }^{6}$ Joseph Schacht, An Introduction to Islamic Law...,h. 118.

7 Ibid, h. 119.

8 Nurcholis Madjid, Tradisi Syarah dan Hasyiyah Dalam Fikih dan Masalah Stagnasi Pemikiran Hukum Islam, dalam Budy Munawar Rahman, Kontekstualisasi Doktrin Islam dalam Sejarah, (Jakarta: Paramadina, 1995), h. 313. 
memoles (talwis) dan mengomentari serta memberikan kanotasi secukupnya tanpa daya kritis sedikitpun. ${ }^{9}$

Aktifitas sharah dan häshiyah ini bermula semenjak meninggalnya para imam mazhab dan para tokoh mazhab generasi pertama seperti Abu Yusuf dan Muhammad ibn Hasan dalam mazhab Hanafi; Ibn Qāsim dan al-Ashāb dalam mazhab Malikī; al-Muzanī dan al-Buwait\}i dalam maz\}h\}ab al-Shafi'ī; dan al-Atsrām dalam mazhab Hanbalī.

Maraknya tradisi syarah dan hāsyiah dikalangan umat Islam saat itu yang oleh Nurcholis Madjid disebut dengan pseudo-ilmiah ditandai dengan semakin menurunnya tingkat kreativitas dan orisinalitas intelektual umat Islam. Stagnasi keilmuan ini sebagai ongkos sangat mahal yang harus dibayar oleh umat Islam sebagai akibat dari ketidakberanian mereka mengambil resiko salah dalam melakukan penelitian (istiqrā') yang kemudian dirumuskan dan dirasionalisasikan dengan argumen sebagaimana yang telah dicontohkan oleh para imam mazhab. ${ }^{10}$ Periode taklid dan fanatisme terhadap mazhab semakin massif di masyarakat Islam dengan diproklamirkan seruan pintu ijtihad sudah tertutup.

Ibrahim Hosen mencatat ada empat alasan utama yang melatari seruan tersebut, Pertama, hukum-hukum Islam dalam bidang ibadah, mu'āmalah, munākahat, jināyat dan lain sebagainya sudah lengkap dan dibukukan secara terinci dan rapi, karena itu ijtihad dalam bidang-bidang tersebut sudah tidak diperlukan lagi. Kedua, mayoritas Ahl al-Sunnah hanya mengakui maz\}hab empat, karena itu penganut maz\}hab Ahl al-Sunnah hendaknya memilih salah satu dari maz\}hab yang empat dan tidak boleh di luar itu. Ketiga, membuka pintu ijtihad, selain hal itu percuma dan membuang waktu (tahsil al-hāsil), hasilnya akan berkisar pada hukum yang terdiri atas kumpulan pendapat dua mazhab atau lebih, hal semacam ini terkenal dengan istilah talfiq di mana kebolehannya masih diperselisihkan di kalangan ulama ushul. Yang terakhir adalah kenyataan sejarah menunjukkan bahwa sejak awal abad ke-4 $\mathrm{H}$ sampai kini, tak seorang ulama pun yang berani memproklamirkan dirinya atau diproklamirkan oleh para pengikutnya sebagai seorang mujtahid mutlaq mustaqil setingkat ke empat imam mazhab. Hal ini menunjukkan bahwa syarat-syarat berijtihad itu memang sangat sulit, untuk tidak dikatakan mustahil adanya. ${ }^{11}$ Argumen ini menurut Ibrahim Hosen ternyata juga diperkuat oleh keputusan hasil sidang Lembaga Penelitian Islam al-Azhar di Kairo pada bulan Maret 1964. ${ }^{12}$

Berkenaan dengan itu, Hasan Hanafi menyebut produk pemikiran Islam masa lalu itu sebagai al-turās\} (warisan budaya) yang memiliki tiga ciri pokok, yaitu: almanqul ilainā (sesuatu yang kita warisi), al-mafhum lanā (sesuatu yang kita fahami)

${ }_{9}$ Menurut Nurcholis Madjid yang menjadi ciri umum masyarakat muslim saat itu ialah suasana traumatis terhadap perpecahan dan perselisihan, sehingga yang muncul sebagai dambaan atau obsesi utama masyarakat ialah ketenangan dan ketentraman. Agaknya dambaan mereka tercapai, tapi dengan ongkos yang amat mahal, yaitu stagnasi atau kemandekan. Sebab ketenangan dan ketentraman itu mereka 'beli' dengan menutup dan mengekang kreativitas intelektual dan penjelasan atas nama doktrin taklid dan tertutupnya ijtihad.

10 Nurcholis Madjid, Tradisi Syarah dan Hasyiyah..., h. 313.

11 Ibrahim Hosen, Memecahkan Persoalan Hukum Baru, dalam Jalaluddin Rahmat dkk, Ijtihad dalam Sorotan, (Bandung: Mizan, 1988), h. 40-41.

12 Ibid. 
dan al-muwajjih lisulūkinā (sesuatu yang mengarahkan perilaku kita). ${ }^{13}$ _Dari sini perputaran roda budaya dan tradisi pemikiran Islam senantiasa menggelinding dalam alur "gerak statis" (harakat sukūn) karena gerak sejarahnya tidak mengkristal pada produksi hal-hal baru, melainkan pada reproduksi hal-hal lama dalam bingkai pemahaman tradisional atas al-turāş. ${ }^{14}$

Kebutuhan akan kerangka metodologi baru yang mempergunakan pendekatan integratif-interkonektif dengan berbagai entitas disiplin keilmuan 'sekuler' menjadi yang tidak bisa dihindari oleh ushul fikih apabila tetap menghendaki bisa survive dalam merespon setiap persoalan sosial kemasyarakatan yang berkembang demikian dinamis dan akseleratif ini agar ushul fikih tetap sesuai dengan jargonnya, alhukmu yadūru ma'a illatihi wujūdan wa 'adaman sehingga bisa tetap shālih likulli az-zamān wa al-makān.

\section{B.4. Perilaku Masyarakat Dalam Periode Taqlid}

Umat Islam dalam periode taqlid tidak bersatu. Kondisi tersebut, sejarawan melaporkan bahwa, fenomena itu adalah salah satu penyumbang terhadap kehancuran Dinasti Abbasiyah disamping faktor yang lain dan awal dari kemunduran tsaqafah (Intelektual) dan hadharah (peradaban) Islam.

Dalam periode taqlid, ta'asub umat Islam kepada mazhabnya sangat berlebihan. Puncak dari keadaan tersebut munculnya fatwa al-Qaffal yang menyerukan ditutupnya pintu ijtihad..$^{15}$

Perasaan ta' asub pada mazhab tertentu dapat dibuktikan dalam pernyataan alKarkhi (w. 365 H/976 M) sebagai berikut :"Setiap ayat (Al-Quran) atau hadis yang menyalahi apa yang dipegangi sahabat-sahabat kita (Hanafi dan Hanafiyah), maka harus ditakwili atau di-mansukh-kan". ${ }^{16}$

Untuk memperkuat mazhab masing-masing, umat Islam melakukan dalam berbagai cara yaitu dengan mengemukakan bukti kebenaran mazhabnya dan menyalahkan yang lain. Terkadang mereka juga memperkuat tokoh mereka dengan menyatakan kelebihan dan keajaiban-keajaiban yang dimilikinya dan lain-lain. Umat Islam disibukkan dengan persoalan tersebut sehingga memalingkan mereka dari asas pembentukan hukum pertama yaitu Al-Quran dan Sunnah Rasul.

Ketika masyarakat Islam larut dalam polemik tersebut, intelektual mereka kian melemah. Jika mereka ingin mengetahui fikih, mereka hanya mencukupi diri dengan mempelajari kitab-kitab yang ditulis oleh imam yang ditaqlidi dan mempelajari metode pengambilan hukum yang diaplikasikan oleh imam mereka yang kemudian mereka dianggap sebagai fuqaha. ${ }^{17}$

${ }^{13}$ Hassan Hanafi, Dirasat Islamiyah, (Kairo: Maktabah al-Anjilo, 1981), h. 107.

14 M.Abid al-Jabiri, al-Turath wa al-Hadathah; Dirasat wa Munaqashat, (Beirut: al-Markaz al-Tsaqafi al-Arabi, 1991), h. 15.

${ }_{15}$ Muhammad Maghfur W, Koreksi atas Kesalahan Pemikiran Kalam dan Filsafat Islam, (Bangil-Jatim : Al-Izzah, 2002), h. 188.

16 Abdul Wahab Khallaf, Khulashah Tarikh TaShri' Islamy, Terj. Imron AM, Ikhtisar Sejarah Pembentukan Hukum Islam, (Surabaya: PT. Bina Ilmu, 1979), h. 79.

17 Abdul Karim Al Khatib, Saddu Bab al-Ijtihad wa ma Tarattaba, Terj. Ach.Maimun Syamsuddin dan Abdul Wahid Hasan, Ijtihad Menggerakkan Potensi Dinamis Hukum Islam, (Jakarta: Gaya Media Pratama, 2005), h. 163. 
Dalam periode taqlid, konsentrasi umat Islam untuk memperbanyak pengikut terhadap mazhab yang dianut juga sangat besar. Motivasi tersebut terkadang terjebak mereka melakukan hal-hal yang tidak ideal misalnya yang dilakukan oleh Al-Qaffal al-Sharsi yang bermazhab Shafi'i. Dia telah menipu Sultan Mahmud bin Sabkatajin pengikut Hanafiy agar berpindah kemazhab Shafi'i. Caranya dengan melakukan wudhu' dan shalat dengan cara yang salah, kemudian dinyatakan bahwa cara wudhu' dan shalat tadi adalah caranya mazhab Hanafiy, kemudian berwudhu' dan shalat dengan sempurna, kemudian menyatakan bahwa wudhu' dan shalat tadi merupakan cara mazhab Shafi'i. Upaya yang dilakukan oleh AlQaffal berhasil, Sultan tersebut berpindah kepada mazhab Shafi'i yang sebelumnya adalah bermazhab Hanafiy. ${ }^{18}$

Demikianlah gambaran masyarakat Islam dalam periode taqlid yang telah melemahkan tsaqafah dan hadharah mereka. Padahal Islam sebagai agama mereka merupakan ajaran yang bersifat universal dan berperadaban.

\section{Simpulan}

Setelah tergeneralisasi madzhab sampai abad ke 7 Pemikiran hukum Islam mengalami kemandekan, statisnya ajaran Islam karena sikap stagnasi umat Islam dalam memperkuat tsaqafah (intelektual) sebagai topangnya hadharah (peradaban). Sikap ini terlihat dari perilaku umat Islam pasca madzhab yang bertaqlid kepada mazhab yang telah ada, dan munculnya budaya syarah dan hasyiyah. Mereka tidak berusaha lagi menyelesaikan prolematika dimasanya berdasarkan realitas yang ada. Nostalgia masa lalu dan anggapan telah mapannya mazhab yang dianut telah mengkristal dalam diri umat Islam dalam periode tersebut. Sehingga ajaran Islam hanyalah sebatas teori dan ritual saja bukan aplikatif sebagai hukum positif bagi umatnya dalam segala aspek kehidupan.

\section{Referensi:}

Al Khatib, Abdul Karim, Saddu Bab al-Ijtihad wa ma Tarattaba, Terj. Ach.Maimun Syamsuddin dan Abdul Wahid Hasan, Ijtihad Menggerakkan Potensi Dinamis Hukum Islam, Jakarta: Gaya Media Pratama, 2005.

Al-Jabiri, M.Abid, al-Turath wa al-Hadathah; Dirasat wa Munaqashat, Beirut: al-Markaz al-Tsaqafi al-Arabi, 1991.

Al-Qaradhawi, Yusuf, Kaifa, Nata'aamalu Ma'a Tiraatsi Wa Tamazzahabi Wal Iktilaafi, Terj. Abdul Hayyie al-Kattani, Atik Fikri Ilyas dan Ahmad Ichwani, Memahami Khazanah Klasik, Mazhab dan Ikhtilaf, Jakarta: Akbar Media Eka Sarana.

Hanafi, Hassan, Dirasat Islamiyah, Kairo: Maktabah al-Anjilo, 1981.

Hosen, Ibrahim, Memecahkan Persoalan Hukum Baru, dalam Jalaluddin Rahmat dkk, Ijtihad dalam Sorotan, Bandung: Mizan, 1988.

Khallaf ,Abdul Wahab, Khulashah Tarikh TaShri' Islamy, Terj. Imron AM, Ikhtisar Sejarah Pembentukan Hukum Islam, Surabaya: PT. Bina Ilmu, 1979.

18 Muhammad Maghfur W, Koreksi atas Kesalahan Pemikiran..., h. 189. 
Madjid, Nurcholis, Tradisi Syarah dan Hasyiyah Dalam Fikih dan Masalah Stagnasi Pemikiran Hukum Islam, dalam Budy Munawar Rahman, Kontekstualisasi Doktrin Islam dalam Sejarah, Jakarta: Paramadina, 1995.

Maghfur, W.Muhammad, Koreksi atas Kesalahan Pemikiran Kalam dan Filsafat Islam, Bangil-Jatim : Al-Izzah, 2002.

Schacht, Joseph, An Introduction to Islamic Law, Terj. Joko Supomo, Pengantar Hukum Islam, Bandung: Nuansa, 2010. 